\title{
Assessment of Functionalities, Utilisation and Management of Hostel Facilities in Nigerian Universities
}

\author{
SUBAIR, S. 'TAYO* \\ Department of Educational Management Faculty of Education Obafemi Awolowo University Ile-Ife, Nigeria \\ *Corresponding Author: SUBAIR, S. 'TAYO, Department of Educational Management Faculty of \\ Education Obafemi Awolowo University Ile-Ife, Nigeria
}

\begin{abstract}
The study assessed the functionality of hostel facilities in Nigerian university. It determined level of utilization, and levels of management of hostel facilities in the study area. These were with a view to providing information on functionalities, utilization and management of hostel facilities in Nigerian universities. The study adopted the survey research design of ex-post-facto. The population for the study consisted of all the 9,934 student residents in Obafemi Awolowo University, Ile-Ife as at 2016/2017 academic session. A sample size of 993, representing $10 \%$ was drawn from the population. A self-designed instrument pilot tested titled: Functionalities, Utilisation and Management of Hostel Facilities Questionnaire (FUMHoFQ) was used. Data collected were analysedusing frequency counts and percentages. The results showed that functionality of hostel facilities was fairly done (54.8\%), 45.3\% value for fair utilization of facilities and that available facilities were not highly maintained (51.5\%).The study concluded that hostel facilities needed to be improved upon and that both reactive and predictive management approaches should be embraced.
\end{abstract}

Key words: Hostel Facilities, Functionality, Utilisation, Management Approaches

\section{INTRODUCTION}

Facility management in any establishment or organization focuses on the needs and safety of the occupants of a place with respect to the space and services supporting his/her person and property. It encompasses multiple disciplines meant to ensure functionality of the built environment by integrating people, place, process and technology (International Facility Management Association, 2010).There are two types of facilities management approaches which are Predictive and Reactive Approaches. Reactive approach refers to fixing things when they breakdown, while Predictive refers to using a good preventive maintenance programme so as to keep facilities optimally functioning, which often results into increase in the life span of the facilities.

Facilities management is the general description for overseeing, maintaining and executing the day-today tasks required for real estate assets to function properly. The tasks performed include administrative management in form of collections, record keeping, reporting and marketing; it's also in form of security and convenience; physical structure management in forms of maintenance, rehabilitation, renovation and space management. Various causes have been given for the perceived poor situation, while some are systemic and in-house, others are external. It has also been observed that perceived public facilities in Nigeria suffer from lack of maintenance culture which has not been developed in the country (Oladipo, 2001).

Student personnel services as an essential component in an educational enterprise focuses on the contentment of students in the areas of medical and health services; students' registration, orientation, accommodation and mentoring for school activities. In the view of Alani, Okunola and Subair (2010), students' low level of contentment and poor attitude to education are attributable to insufficient facilities in universities. It is therefore indubitable that the complexity of students' personnel services has placed more responsibilities on the administrators. Provision of sufficient hostel facilities is a sure and conscious means of ameliorating the bad situation. It is in against this background that this study is focused on functionalities, utilisation and management approaches of hostel facilities in Nigerian universities. This is with a view to providing information on current state 
of functionalities, rate of utilization and management levels of hostel facilities in Nigerian universities.

\section{LITERATURE REVIEW}

The significance of housing covers the whole parts of human life. Principally, it includes physical insurance from risks which conventionally might be viewed as sanctuary. On the whole, housing as a unit of nature of man, affects the wellbeing, social conduct, fulfillment and general welfare of the network. It mirrors the social, and financial estimations of a general public as it is the best physical and verifiable proof of progress in a nation (Aluko, 2009). It is basic for hostel facilities to give the fundamental foundations required by the students. Such include toilets, running water, power, convenient rooms, baths, rich kitchenette and an entertainment territory arrangement; all being something that is not in every case promptly accessible. It is a genuinely normal event for these facilities to either be inaccessible or in a condition of decay. The requirement for a powerful and helpful hostel facilities cannot be overemphasized because of the way that students are relied upon to be in a sound perspective to exceed expectations in their scholastic undertaking which can be accomplished by a decent lodging framework. Since student lodging gives physical assurance as well as a solid social and befitting conduct, the efficiency of an arrangement of students may not be absolutely detached with their student hostel condition.

In 2001, the Ministry of Education Board in the nation tried to find out the level of scholarly worry in first year students of Nigerian universities, during which terrible state of hostel facilities was observed to be one of the significant reasons for worry among undergraduates. The investigation revealed an abnormal state of apparent scholarly worry among first year students in Nigerian federal universities which is due to lack of array of facilities in the hostel. Subsequently, hostel facilities are genuinely insufficient and the accessible ones were in terrible conditions. Students lodging is getting to be a standout amongst the most imperative industry that deliver openings for work as per another exploration report by the National Multi Housing Council (NMHC). The examination of more than 2000 exclusive properties demonstrates that hostel is a potential one in innovative market work that could enable the business to check the impact of rising homeownership rates. Amid the outline procedure of human haven, certain determinants merit thought, regardless of prevailing financial condition and orderlies, materials and innovations. To this, atmosphere has been analyzed to be a determinant of building structure and of the selection of materials and constructional systems. Investigating into the past, numerous creators have given different thoughts regarding the source of mass hostels for the general population and the students in higher organization, as respect their vital and issues (Omole, 2000;Aluko 2009).

In perspective of this, one can't discuss students lodging without its administrative perspective, the assessment that lodging administration like some other business ventures is worried about right inspiration of staff and reasonableness to inhabitants by counseling, illuminating and empowering them so that a feeling of unity of purpose is set up. Most importantly, it is fundamental or basic that the correct sort of association be set up by university administration with hostel maintenance unit that would see to the management of the hostel facilities. Hostel facilities in Nigeria has not gotten the coveted consideration both from the legislature and the executive arms of government. This along these lines makes it basic for schools to give students hostel a best need while improving the notoriety of the school among different peers. The students hostel is said to incorporate facilities, for example, rooms which can fill the double need of study and dozing restrooms and toilets, kitchen, clothing, recreational zones and access to web benefits as this further upgrade the learning. Abramson (2009) on his part, expressed that the students hostel lodging can be additionally made energizing by giving further facilities, for example, ATM machines, auto stop, smaller than expected markets, bookshops and cafeterias inside the region of the students' lodging.

Also, hostel facilities are the material resources provided for students to optimize their productivity in the learning process (Asiabaka, 2008). He alluded further that hostel facilities consist of all types of buildings for academic and nonacademic activities, equipment for academic and nonacademic activities, areas for sports and games, landscape, farms and gardens including trees, roads and paths. Others include furniture and toilet facilities, lighting, acoustics, storage facilities and parking lot, security, transportation, ICT, cleaning materials, food services, and special facilities for the physically challenged persons. From the afore-mentioned, the types of facilities the hostels needs must include instructional, recreational, residential and general-purpose. 
Uche (2007) findings showed that basic facilities of recreation and hygiene are lacking in higher institutions hence recommends that the administration of higher institutions should use their initiatives, creative minds and leadership principles to direct more attention where development is needed, most especially as it concerns students' welfare and environmental hygiene on campus.

The tertiary education is for the all-round development of the recipient and when facilities in these institutions are not student oriented, the aim is defeated. Thus, inadequacy of any category of hostel facilities could lead to overcrowding, stress, unruly behaviour, distractions and gradual decay of symbolic things that help pattern student behavior (Babatope, 2010). Sometimes, focus is only on provision but Subair (2008) opined that functionality, utilization and proactive management approaches are required if hostel facilities as important physical structures in the universities are to enjoy longevity. Anything short of this would result into forcing students to deviate from normal functioning. Isaiah (2013) reiterated that physical state of buildings affects the students' self-esteem, peer interactions, discipline, motivation and interpersonal relationships.

Adenuga, Olufowobi and Raheem (2010) shed light on the areas of problems of facility managers in key building elements and also provide a checklist of operation for them. These areas include washrooms and toilets; corridors and rooms; ceiling, interior roofs and canopies; plumbing; electricity; windows; doors and partitions; roofs and gutters; water mains; septic tanks; erosion; cooling system. The study suggests that facility managers should pay keen attention to these areas. Similarly, De Silva (2011) shows 15 commonest areas of problems of facility managers which can be minimized if they are engaged at the developmental stage of projects. These include defects in waterproofing; doors, windows and joinery; piping/plumbing and ductwork; tiles; sanitary wares; fittings and jointing; claddings and curtain walls; ceiling components; services, plastering; biological and chemical attacks; masonry; paints; structural concrete; floor components and structural steel.

Omu (2006) carried out a study on the management of physical and equipment in schools in Cross Rivers State. He found that most physical facilities are in state of disrepair, buildings are obsolete, school equipment are occasionally repaired; however, shortage of funds and poor facilities management approaches were responsible for the poor functionality and inaccessibility to the facilities. Ejionueme (2010) carried out a research on the administration of student personnel services in federal and state universities. His focus on hostel facilities for students showed they were available but tremendous impact on the students. Among these are that its inadequacies and malfunctionalities have caused students inability to concentrate on their studies effectively; exposure of students to hazards, lateness to lectures, encourage antisocial behaviours, breeds bad blood between the students and university management; and generate crises and protest in institutions. All of these findings show some implications for the society which makes use of products of these universities in achievement of national development. Where the state of student personnel services is seen as part of the causes of the present quality of students' total life and development, all stake holders including the private sector, should be moved to be more actively involved in the provision of student personnel services in the nation universities' particularly, hostel facilities. The present study on hostel accommodation is one of the students' personnel services and improving the management of hostel facilities in the tertiary institutions is key.

\subsection{Statement of the Problem}

Befitting hostel facilities are central to conducive learning. Some of these include bed and beddings, electrical fittings and regular electricity supplies, functioning plumbing materials, reading tables, chairs, window with mosquito nets, functional toilets, good reading room, security coverage, cleaning services and internet facilities. Moreover, living in university hostels has been said to afford the students the opportunity to learn how to be less dependent on family members without being completely on their own. In addition, it becomes easier for students to mingle and have close bonds with fellow students thereby aiding functional living in the community. Since 1970s, hostel facilities and its management in Nigerian universities have become worrisome due to unprecedented students' enrolment. The situations have caused crisis and disruption of academic calendar, with its attendant consequences. Observations have shown that students' complaints in the past arose from inadequate hostel facilities conditions and their maintenance; which has equally resulted into protests emanating from anxieties stirred by the combined effect of population explosion in the hostels and deteriorating facilities due to poor maintenance culture. While the increase in population of students had been growing in geometric proportion, the provision of befitting hostel and adequate facilities had been 
growing in arithmetic progression. This has also led to the emergence of a set of students known as 'Squatters' in the hostels, while the officially allocated bed spaces occupants are referred to as 'Bed Lords'. The attendant effects of incessant school closures and disruption of academic calendar are poor self-esteems by the students residing in those hostels, exposure to health and environmental hazards as a result of overpopulation among others make it pertinent to thus empirically examine the situation of hostel facilities in terms of functionalities, utilization viz-a-vis its management approaches with a view to improving on the current situation.

\subsection{Research Questions}

The following questions were raised to guide the study:

1. How functional are the present hostel facilities in Nigerian universities?

2. What is the level of utilisation of the hostel facilities in Nigerian universities?

3. How are the hostel facilities managed in Nigerian universities?

\section{Methodology}

The study employed a survey of ex-post-facto design. The population of this study comprised 9,934 students residing in OAU hostels as at 2016/2017 academic session. The hostels are Awolowo, Fajuyi, Angola, ETF, Mozambique, Post Graduate, Akintola, Moremi and Alumni (situated within OAU, Ile-Ife). A self-designed instrument pilot-tested and used was the Hostel Facilities and Management Questionnaire (HosFAM-Q), which consisted of two sections: the demographic information and 25 items that were used to elicit information from the hostel residents. The sample size for the study consisted of 993 students officially provided with bed spaces in the hostels. Proportionate Sampling procedure was used to determine the number of students used in each hall of residence. A sample size frame of $10 \%$ of the number of students allocated bed spaces in each hostel was selected for the study. Convenience sampling technique was used in administering the instrument. Out of the 1,033 administered, 667 were returned, which is $63.9 \%$ return rate. This was because of the high mobility level of students. Data obtained were sorted in order to remove irrelevant responses. Frequency distribution and percentages were used to answer the research questions.

\section{RESUlts}

Research Question 1: How functional are the present hostel facilities in Nigerian universities? To answer this question, respondents' responses were analysed using percentages. The results are presented in Table 1.

Table1. Functionality of Hostel Facilities

\begin{tabular}{|l|l|l|l|l|}
\hline S/N & Facilities & Highly Functional $(\%)$ & Fairly Functional $(\%)$ & Not Functional $(\%)$ \\
\hline 1. & Bed & $318(47.7)$ & $279(41.8)$ & $70(10.5)$ \\
\hline 2. & Beddings & $198(29.7)$ & $366(54.9)$ & $103(15.4)$ \\
\hline 3. & Wardrobe & $322(48.3)$ & $318(47.7)$ & $27(4.0)$ \\
\hline 4. & Electrical fittings & $201(30.1)$ & $407(61.0)$ & $59(8.8)$ \\
\hline 5. & Kitchenette & $134(20.1)$ & $316(47.4)$ & $217(32.5)$ \\
\hline 6. & Electricity Supply & $334(50.1)$ & $324(48.6)$ & $9(1.3)$ \\
\hline 7. & Water supply & $240(36.0)$ & $376(56.4)$ & $51(7.6)$ \\
\hline 8. & Cafeteria & $61(9.1)$ & $506(75.9)$ & $100(15.0)$ \\
\hline 9. & Reading Room & $245(36.7)$ & $384(57.6)$ & $38(5.7)$ \\
\hline 10. & Common Room & $300(45.0)$ & $349(52.3)$ & $18(2.7)$ \\
\hline 11. & Plumbing fittings & $166(24.9)$ & $358(53.7)$ & $143(21.4)$ \\
\hline 12. & Waste disposal & $231(34.6)$ & $325(48.7)$ & $111(16.6)$ \\
\hline 13. & Bathroom & $234(35.1)$ & $369(55.3)$ & $64(9.6)$ \\
\hline 14. & Toilets & $165(24.7)$ & $469(70.3)$ & $33(4.9)$ \\
\hline 15. & Book shelf & $182(27.3)$ & $348(52.2)$ & $137(20.5)$ \\
\hline 16. & Fire safety equipment & $28(4.2)$ & $387(58.0)$ & $252(37.8)$ \\
\hline 17. & Parking lots & $279(41.8)$ & $335(50.2)$ & $53(7.9)$ \\
\hline 18. & Internet & $220(33.0)$ & $340(51.0)$ & $107(16.0)$ \\
\hline 19. & Reading Chairs/Tables & $169(25.3)$ & $381(57.1)$ & $117(17.5)$ \\
\hline 20. & Cleaning services & $193(28.9)$ & $487(73.0)$ & $29(4.3)$ \\
\hline 21. & Mini/Super market & $150(22.5)$ & $370(55.5)$ & $30(4.5)$ \\
\hline 22. & Sporting & $58(8.7)$ & & $239(35.8)$ \\
\hline & & &
\end{tabular}




\begin{tabular}{|l|l|l|l|l|}
\hline 23. & Mobile network & $73(10.9)$ & $483(72.4)$ & $111(16.6)$ \\
\hline 24. & ATM & $75(11.2)$ & $260(39.0)$ & $332(49.8)$ \\
\hline 25. & CCTV & $11(1.6)$ & $253(37.9)$ & $403(60.4)$ \\
\hline 26. & Average Percentage & $\mathbf{2 7 . 8 \%}$ & $\mathbf{5 4 . 8 \%}$ & $\mathbf{1 7 . 3 \%}$ \\
\hline
\end{tabular}

Table1shows the functionality level of hostel accommodation facilities that were available in Nigerian university. The hostel accommodation facilities that were highly functional include electricity supply $(50.1 \%)$, wardrobe $(48.3 \%)$ and bed $(47.7 \%)$. The respondents also identified other accommodation facilities that were fairly functional to include cafeteria (75.9\%)mini/super market $(73.0 \%)$, mobile network $(72.4 \%)$, toilets $(70.3 \%)$,cleaning services $(66.7 \%)$, electrical fittings $(61.0 \%)$, fire safety equipment (58.0), reading room (57.6) reading chairs and table $(57.1 \%)$, water supply $(56,4)$ sporting (55.5\%), bathroom (55.3), bedding (54.9), plumbing fittings (53.7), common room (52.3), book shelf $(52.2 \%)$, internet $(51.0 \%)$, parking lots $(50.2 \%)$, waste disposal $(48.7 \%)$ and kitchenette (47.4). However, some accommodation facilities such as CCTV (60.4\%) and ATM (49.8\%) were not functional according to the respondents. It can therefore be established that hostel accommodation facilities are fairly functional on campus with $54.8 \%$ as against $27.8 \%$ highly functional and $17.3 \%$ for not functional. It could be established that hostel accommodation facilities were fairly functional in Nigerian university as it has highest percentage $54.8 \%$.

Research Question 2: What is the level of utilisation of the hostel facilities in Nigerian universities? To answer this question, respondents' responses were analysed using percentages. The results are presented in Table 2.

Table2. Level of Utilization of Hostel Facilities in Nigerian Universities

\begin{tabular}{|l|l|l|l|l|}
\hline S/N & Facilities & Highly Utilized (\%) & Fairly Utilized (\%) & Not Utilized (\%) \\
\hline 1. & Bed & $371(55.6)$ & $213(31.9)$ & $83(12.4)$ \\
\hline 2. & Beddings & $217(32.5)$ & $337(50.5)$ & $113(16.9)$ \\
\hline 3. & Wardrobe & $351(52.6)$ & $306(45.9)$ & $10(1.5)$ \\
\hline 4. & Electrical fittings & $326(48.9)$ & $318(47.7)$ & $23(3.4)$ \\
\hline 5. & Kitchenette & $155(23.2)$ & $325(48.7)$ & $187(28.0)$ \\
\hline 6. & Electricity Supply & $418(62.7)$ & $217(32.5)$ & $32(4.8)$ \\
\hline 7. & Water supply & $456(68.4)$ & $192(28.8)$ & $19(2.8)$ \\
\hline 8. & Cafeteria & $146(21.9)$ & $356(53.4)$ & $165(24.7)$ \\
\hline 9. & Reading Room & $286(42.9)$ & $305(45.7)$ & $76(11.4)$ \\
\hline 10. & Common Room & $324(48.6)$ & $331(49.6)$ & $12(1.8)$ \\
\hline 11. & Plumbing fittings & $164(24.6)$ & $426(63.9)$ & $77(11.5)$ \\
\hline 12. & Waste disposal & $286(42.9)$ & $264(39.6)$ & $117(17.5)$ \\
\hline 13. & Bathroom & $359(53.8)$ & $223(33.4)$ & $85(12.7)$ \\
\hline 14. & Toilets & $310(46.5)$ & $338(50.7)$ & $19(2.8)$ \\
\hline 15. & Book shelf & $214(32.1)$ & $365(54.7)$ & $88(13.2)$ \\
\hline 16. & Fire safety equipment & $165(24.7)$ & $307(46.0)$ & $195(29.2)$ \\
\hline 17. & Parking lots & $262(39.3)$ & $395(59.2)$ & $10(1.5)$ \\
\hline 18. & Internet & $288(43.2)$ & $313(46.9)$ & $66(9.9)$ \\
\hline 19. & Reading Chairs/Tables & $198(29.7)$ & $362(54.3)$ & $107(16.0)$ \\
\hline 20. & Cleaning services & $228(34.2)$ & $348(52.2)$ & $91(13.6)$ \\
\hline 21. & Mini/Super market & $225(33.7)$ & $413(61.9)$ & $29(4.3)$ \\
\hline 22. & Sporting & $182(27.3)$ & $334(50.1)$ & $151(22.6)$ \\
\hline 23. & Mobile network & $184(27.6)$ & $297(44.5)$ & $186(27.9)$ \\
\hline 24. & ATM & $48(7.2)$ & $122(18.3)$ & $497(74.5)$ \\
\hline 25. & CCTV & $22(3.3)$ & $141(21.1)$ & $504(75.6)$ \\
\hline 26. & Average Percentage & $\mathbf{3 7 . 1 \%}$ & $\mathbf{4 5 . 2 6 \%}$ & $\mathbf{1 7 . 6 \%}$ \\
\hline
\end{tabular}

Table2shows the utilization level of hostel facilities that were available in Nigerian university. The hostel facilities that were highly utilized include water supply (68.4), electricity supply (62.7\%), bed (55.6\%), bathroom (53.8), wardrobe (52.6) electrical fittings (48.9) and waste disposal (42, 9\%). The respondents also identified other accommodation facilities that were fairly utilized to include plumbing fittings (63.9), mini/super market (61.9), parking lots (59.2\%), book shelf (54.7), reading chairs and table $(54.3 \%)$, cafeteria (53.4), cleaning services $(52.2 \%)$, toilets $(50.7 \%)$, sporting (50.1\%), bedding (50.5), common room (49.6\%), kitchenette (48.7), reading room (45.7) and mobile network (44.5\%). However, some hostel facilities such as CCTV (75.6\%) and ATM (74.5\%) were not 
utilized according to the respondents. It can therefore be established that hostel accommodation facilities are fairly utilized on campus with $45.3 \%$ as against $37.1 \%$ and $17.6 \%$ being highly utilizedand not utilized respectively. It could be established that hostel facilities were fairly utilized in Nigerian university as it has highest percentage $45.3 \%$.

Research question 3: How are the hostel facilities managed in Nigerian universities? To answer this question, respondents' responses were analysed using percentages. The results are presented in Table 3.

Table3. Hostel Facilities Management in Nigerian Universities

\begin{tabular}{|c|c|c|c|c|}
\hline $\mathbf{S} / \mathbf{N}$ & Facilities & High Maintenance (\%) & Fair Maintenance (\%) & Low Maintenance $(\%)$ \\
\hline 1. & Bed & $126(18.9)$ & $320(48.0)$ & $221(33.1)$ \\
\hline 2. & Beddings & $59(8.8)$ & $386(57.9)$ & $222(33.3)$ \\
\hline 3. & Wardrobe & $52(7.8)$ & $382(57.3)$ & $233(34.9)$ \\
\hline 4. & Electrical fittings & $76(11.4)$ & $266(39.9)$ & $325(48.7)$ \\
\hline 5. & Kitchenette & $77(11.5)$ & $201(30.1)$ & $389(58.3)$ \\
\hline 6. & Electricity Supply & $118(17.7)$ & $418(62.7)$ & $131(19.6)$ \\
\hline 7. & Water supply & $93(13.9)$ & $371(55.6)$ & $206(30.4)$ \\
\hline 8. & Cafeteria & $17(2.5)$ & $336(50.4)$ & $314(47.1)$ \\
\hline 9. & Reading Room & $69(10.3)$ & $354(53.1)$ & $244(36.6)$ \\
\hline 10. & Common Room & $97(14.5)$ & $383(57.4)$ & $187(28.0)$ \\
\hline 11. & Plumbing fittings & $82(12.3)$ & $308(46.2)$ & $277(41.5)$ \\
\hline 12. & Waste disposal & $100(15.0)$ & $377(56.5)$ & $190(28.5)$ \\
\hline 13. & Bathroom & $125(18.7)$ & $235(35.2)$ & $307(46.0)$ \\
\hline 14. & Toilets & $105(15.7)$ & $339(50.8)$ & $223(39.6)$ \\
\hline 15. & Book shelf & $107(16.0)$ & $318(47.7)$ & $242(36.3)$ \\
\hline 16. & Safety equipment & $60(9.0)$ & $267(40.0)$ & $340(51.0)$ \\
\hline 17. & Parking lots & $73(10.9)$ & $477(71.5)$ & $117(17.5)$ \\
\hline 18. & Internet & $55(8.2)$ & $444(66.6)$ & $168(25.2)$ \\
\hline 19. & ReadingChairs/Tables & $37(5.5)$ & $382(57.3)$ & $248(37.2)$ \\
\hline 20. & Cleaning services & $62(9.3)$ & $470(70.5)$ & $135(20.2)$ \\
\hline 21. & Mini/Super market & $117(17.5)$ & $391(58.6)$ & $159(23.8)$ \\
\hline 22. & Sporting & $374(56.1)$ & $293(43.9)$ & $0(0)$ \\
\hline 23. & Mobile network & $20(3.0)$ & $390(58.5)$ & $257(38.5)$ \\
\hline 24. & ATM & $13(1.9)$ & $260(39.0)$ & $394(59.1)$ \\
\hline 25. & CCTV & $4(0.6)$ & $227(34.0)$ & $436(65.4)$ \\
\hline 26. & Average Percentage & $12.7 \%$ & $51.5 \%$ & $35.8 \%$ \\
\hline
\end{tabular}

Table3shows the management level of hostel facilities that were available in Nigerian university. The hostel facilities that were highly maintained only include sporting (56.1). The respondents also identified other hostel facilities that were fairly maintained to include parking lots $(71.5 \%)$,cleaning services (70.5\%),internet (66.6), electricity supply (62.7), mini/super market (58.6\%), mobile network $(58.5 \%)$, beddings $(57.9 \%)$, common room $(57.4 \%)$, wardrobe $(57.3 \%)$, reading chairs and table $(57.3 \%)$, waste disposal $(56.5 \%)$, water supply (55.6\%), reading room $(53.1 \%)$, toilet $(50.8 \%)$, cafeteria $(50.4 \%)$, bed $(48.0 \%)$, book shelf $(47.7 \%)$ and plumbing fittings $(46.2 \%)$. However, some hostel facilities such as CCTV (65.4\%), ATM (59.1\%), kitchenette (58.3\%), fire safety equipment (51.0\%) electrical fittings (48.7\%) and bathroom (46.0\%) were not maintained according to the respondents. It can therefore be established that hostel facilities are fairly maintained on campus with $51.5 \%$ as against $35.8 \%$ low maintenance $35.8 \%$ and $12.7 \%$ for high maintenance. It could be established that hostel facilities were fairly maintained in Nigerian university as it has highest average percentage of $51.5 \%$.

\subsection{Discussion of Findings}

On functionality level of hostel facilities, this study established that hostel facilities were fairly functional on campus with $54.8 \%$. The fact that the level of functionality is fair indicated that the existing facilities need be improved upon. Therefore, it did not meet fully the needs of the students. The finding is in line with Uche (2007) who's findings established that basic facilities of recreation and hygiene are not well functional in higher institutions hence recommends that the administration of higher institutions should use their initiatives, creative minds and leadership principles to direct more attention where development is needed, most especially as it concerns students' welfare and 
environmental hygiene on campus. Also, Babatope's (2010) findings showed that tertiary education is for all-round development of the recipients but when facilities in these institutions are not studentoriented and functional, the aim becomes defeated. Thus, low level of functionality of hostel facilities could lead to overcrowding, stress, unruly behaviour, distractions and gradual decay of symbolic things that help pattern students' behavior.

Findings of research question two showed that $45.3 \%$ of the respondents affirmed that the hostel facilities were fairly utilized in Nigerian university. This is in line with the submission of Subair (2008) who opined that most of the time, focus is always on provision but utilization of hostel facilities is not given required attention through proactive management approaches. If hostel facilities are to be enjoyed for a very long time, priority should be given to utilization of these facilities so that they will not be overstretched over time.

Finally, findings on research question three on management of hostel facilities, $51.5 \%$ of respondents affirmed that facilities in Nigerian universities were not highly maintained as it was corroborated by Oladipo (2001) that facilities management is the general description for overseeing, maintaining and executing the day-to-day tasks required for hostel facilities to function properly. The tasks performed include administrative management in form of collections, record keeping, reporting and marketing; it's also in form of security and convenience; physical structure management in forms of maintenance, rehabilitation, renovation and space management. Various causes have been given for the perceived poor situation, while some are systemic and in-house, others are external. It has also been observed that perceived public facilities in Nigeria suffer from lack of proper management inform of adequate maintenance culture which has not been developed in the country. Similarly, Omole, (2000) and Aluko (2009) affirmed that one can't discuss students lodging without its administrative perspective that is, management. The assessment that lodging administration like in some other business ventures is important because it requires right inspiration of staff and reasonableness of the inhabitants, which is done through counseling, illuminating and empowering them so that a feeling and sense of unity of purpose is imbibed and developed. More importantly, it is fundamental or basic that the correct sort of association be set up by university administration with hostel maintenance unit that would see to the management of the hostel facilities. Hostel facilities in Nigeria has not gotten the coveted consideration both from the institutional administration and students arms.

\section{CONCLUSION}

This study established that hostel facilities were fairly functional, utilized and maintained on campus; an indication that the existing facilities need be improved upon. Therefore, it did not meet fully the needs of the students. If hostel facilities are to be enjoyed for a very long time, priority should be given to utilization of these facilities so that they will not be overstretched over time. It is thus advocated that for there to be effective facility management, an Integrated Approach would be needed, that is, to combine both reactive and predictive so as to ensure a more synergetic line of action to keep things running optimally for students use.

\section{Recommendations}

Sequel to the findings of this study, it is recommended that institutional administration device better measures to ensure hostel facilities are properly looked into. Functionalities, utilization and maintenance should be given priority such that the facilities are not over stretched and monitored for necessary repairs and maintenance.

\section{REFERENCES}

[1] Abramson, P. (2009). Downsizing residence halls: space and costs, Living on Campus, College Housing Report. 12.(5), 20-27

[2] Adeniyi, A. O (2018) Hostel accommodation and facilities management approaches in Obafemi Awolowo University, Ile-Ife, Nigeria. An unpublished M.A Ed. Thesis, Obafemi Awolowo University, Ile-Ife, Nigeria.

[3] Adenuga, O. A., Olufowobi, M. B. \& Raheem, A. A. (2010). Effective maintenance policy as abtool for sustaining housing stock in downtown economy. Journal of Building Performance, 1 (1), 93-109.

[4] Alani, R. A, Okunola, P. O \&Subair, S. O (2010). Situation analysis of students' welfare services in universities in South-western Nigeria: Implications for students' personnel management practice. USChina Education Review, 7(10); 42- 50. 
[5] Aluko, Ola E. (2011): The assessment of housing situation among students in the University of Lagos, An International Multi-Disciplinary Journal, Ethiopia. 5 (3). 20, 104-118.

[6] Amole, D. (2009), Residential satisfaction and levels of environment in students' residences, Journal of Environment and Behaviour,41. (6), 1-14.

[7] Asiabaka, I. P. (2008). The need for effective facility management in schools in Nigeria. New Automation in Construction, 8. 511-524.

[8] Babatope, B. A. (2010). Problems of facilities in South-West Nigerian universities and the way forward. Journal of Education and Administrative Professional Studies, 2(2),39-43

[9] De Silva, N. (2011). Promoting the facilities management profession in the project development phase of high-rise building in Sri Lanka. Built Environment, 09 (01), 37-44.

[10] Ejionueme, L. (2010). Management of student personnel services in Federal and State Universities. Unpublished Ph.D thesis, Department of Management, University of Nigeria, Enugu Campus.

[11] Isaiah, M. N. (2013). Linking the school facilities conditions to teachers' level of job dissatisfaction in the South Central Region of Botswana. International Review of Social Science and humanity. 4(2),196-205

[12] Oladipo, S. A. (2001). Maintenance of school plant: A vital strategy of achieving efficiency in the universal basic education scheme, African Journal of Education Management 9 (2), 185-195.

[13] Omole, F. K. (2001). Basic issues in Housing Development, Ondo State Femobless Publication, Nigeria.

[14] Omu, M. (2006). Management of physical facilities and equipment in secondary school in

[15] Cross River State. (Unpublished Ph.D Thesis), Department of Management, University of Nigeria, Nzuka.

[16] Subair, S. 'Tayo (2008) Infrastructure, welfare services and students' perceived motivation to learning in universities in south-west Nigeria. Unpublished Ph.D Thesis, University of Lagos.

[17] Uche, C. M. (2007). Globalization and higher education administration in Southern Nigeria. A paper presented at HERPNET Regional Conference, Ibadan, IITA 13th - 15th August.

Citation: SUBAIR, S. 'TAYO. "Assessment of Functionalities, Utilisation and Management of Hostel Facilities in Nigerian Universities" International Journal of Humanities Social Sciences and Education (IJHSSE), vol 7, no. 6, 2020, pp. 102-109. doi: http://dx.doi.org/10.20431/2349-0381.0706011.

Copyright: (C) 2020 Authors. This is an open-access article distributed under the terms of the Creative Commons Attribution License, which permits unrestricted use, distribution, and reproduction in any medium, provided the original author and source are credited. 